\title{
TWO CASES OF GIANT INTRATHORACIC FIBROMA
}

\author{
BY
}

\author{
LESLIE J. TEMPLE AND G. PENRHYN JONES
}

\author{
From the Liverpool Thoracic Surgical Centre, Broadgreen Hospital, Liverpool
}

(RECEIVED FOR PUBLiCATION AUgUSt 20, 1953)

Improved methods of diagnosis have resulted in an increased awareness of intrathoracic benign tumours, but, apart from bronchial adenomas and hamartomatous tumours, most of the published reports on the other varieties emphasize their rarity. These include lipomas, chondromas, fibromas, and various neurogenic tumours.

Intrathoracic fibromas are tumours of mesenchymal origin, and have therefore been encountered in the various structures of the thoracic cage and its contents. They cannot be sharply differentiated from other mesenchymal growths and some show metaplastic mucinous changes, chondrification, and ossification, with an occasional mixture of adipose cells. Furthermore, the difference between the highly cellular anaplastic fibrosarcomatous growths and the densely fibrous benign growths is one of degree only. Although most of the highly differentiated fibromas behave as benign tumours, cellular areas in them may assume a sarcomatous change.

Small intrathoracic fibromas are usually symptomless and may be detected by routine radiography or at necropsy. Some of the small diaphragmatic fibromas are in fact no more than organizing fibrin balls. Excessive fibrotic reaction to an infective focus may simulate a benign neoplasm, as in the case of Sante (1931).

Harper (1939) estimated that fibromas constituted about $10 \%$ of benign tumours of the ribs, and Baxter and Munro (1950) reported a large fibroma of the chest wall which was a dumb-bellshaped mass with an intrathoracic portion.

Blades (1946) found one case of fibroma (probably neurofibroma) in 106 mediastinal tumours, and the same author (1941) had found 32 cases of mediastinal fibromas in the literature. Neurogenic tumours were included in this figure. Horst and Beatty (1951) have reported a mediastinal haemangio-fibroma $18 \mathrm{~cm}$. in diameter.

Fibroma of the diaphragm was first recorded by Granche (1868). Multiple fibromyomas of the diaphragm were described by Bonamy (1912) but were regarded as pure fibromas by his chief, Philibert. One of these tumours weighed $1,200 \mathrm{~g}$. $\vec{\Omega}$ Alexander (1896) reported a fibrosarcoma of the diaphragm, but after examination of the materialby Hyman and Lederer (1941) it was considered $\subseteq$ to be a benign fibroma. A large growth of the diaphragm described by van Nes (1921) as a fibro- $\overrightarrow{0}$ sarcoma had for its only malignant feature a slight irregularity of the size of the cells. Angiofibroma of the diaphragm has been reported by Burvill-o Holmes and Brody (1932), and by Tuohimaa (1950).

In the discussion following Gale and Edwards paper (1939), Kinsella (1939) described a massive fibromyoma of the right hemidiaphragm grosslyo resembling a uterine fibroid and weighing $2 \mathrm{lb}$.

Large intrathoracic fibromas have been described by Davidson (1935), Susman (1940), Clagett and. Hausmann (1944), Fawcett (1945), Weiss and Del haye (1946), Brewer, Jones, and Dolley (1948), and Verna, Menso, Cueto Böttiger, and Luduena Funes: (1950). The largest was Clagett and Hausmann's case. The tumour was removed piecemeal and weighed 4,972 g. Eskelund (1951) has reported a right lung resembling cystic disease that was pos-o sibly an oedematous fibroma, and Andrus, in a? discussion on Alexander's paper (1941), describecto a fibrolipoma of the chest weighing $4,000 \mathrm{~g}$. Pol litzer and Vaccarezza (1946) described a largês intrathoracic fibrolipoma which weighed 2,400 gN

Typical intrathoracic fibromas seem to be ex N ceedingly uncommon, and all published reports ${ }^{\omega}$ are of single cases. Two further cases are now described, both having some features in commont with those previously reported.

\section{CASE Reports}

CASE 1.-A West African seaman, aged 38, sus tained an accident in which he fell on his left side $\stackrel{\mathbb{Q}}{Q}$ injuring his chest. Two weeks later he had developedo a cough with increasing dyspnoea. A radiograph was taken and this showed an enormous mass in the lefio hemithorax (Fig. 1). A pneumoperitoneum was in 


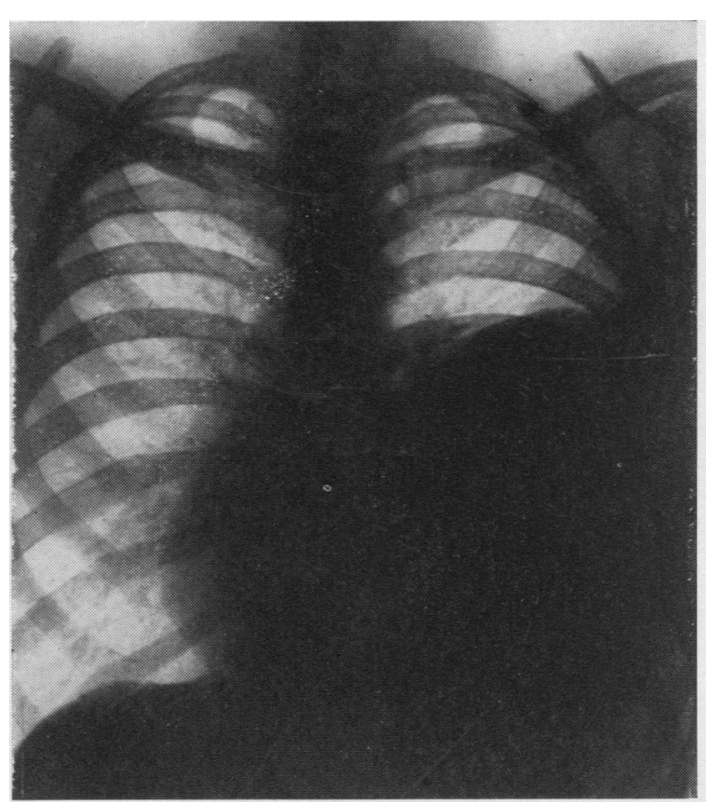

FIG. 1.-Pre-operative film showing large tumour in the left hemithorax with some mediastinal displacement to the right.

duced and showed clearly that the lesion was above the diaphragm. Calcification was noted in the shadow. Mr. Ronald Edwards operated on July 15, 1948. The tumour was grossly adherent to an atelectatic lower lobe of the left lung, to the chest wall, and to the diaphragm. The adhesions were very dense and very vascular. Large vessels ran from the tumour into the substance of the lung. Exposure was difficult because of the size of the tumour, and as well as resecting one rib three others had to be divided before the tumour could be delivered. It was removed en masse with the lower lobe. There was very considerable loss of blood. The chest was closed, and the patient made a normal recovery. He has been followed up to date, remaining in good health without any signs of recurrence.

The tumour on examination was encapsulated and solid, it weighed $2,150 \mathrm{~g}$. and measured $20 \times 15 \times 11$ $\mathrm{cm}$. The pathologist's report is as follows:

"Section shows that the growth is encapsulated and apparently unconnected with the bronchial tree in the lung, but is arising in the pleura. It is composed of homogeneous translucent white matter, and contains areas of calcification and some degenerative cystic change. Histologically the growth is largely acellular and is composed of collagen, but there are some very cellular areas composed of spindle cells. There is some mucoid degenerative change and calcification present, but no evidence of malignancy. It is a fibroma."

CASE 2.-A man aged 45 , a steel worker and salmon fisherman, had noticed shortness of breath in the last few months which had not impeded his normal occu- pation until two months before admission. He then had a very severe attack of dyspnoea and had been unable to work since. On admission he was found to be a stout, muscular man who was dyspnoeic on the very slightest exertion and very easily became cyanosed. The fingers were markedly clubbed. His blood count was within normal limits, but his blood pressure was slightly raised $(180 / 100 \mathrm{~mm}$. $\mathrm{Hg}$.), and there was poor air entry on the right side of the chest, with dullness to percussion and diminished movement. A radiograph showed a large, welldefined tumour occupying the whole of the lower part of the right hemithorax (Fig. 2). The Casoni test was negative. Cardio-pulmonary function tests were requested but he was considered unfit for any extensive investigations. As the possibility of a large cyst was considered, it was decided to insert a needle in the hope that aspiration might relieve some of his symptoms and allow a fuller investigation. A needle was inserted, but no fluid obtained. The sensation conveyed by the needle was that of passage through a solid mass. Shortly after aspiration he complained of pain and tightness in the chest. His pulse was imperceptible and signs of shock were obvious. A blood transfusion was given, and $32 \mathrm{oz}$. of fresh blood aspirated from the pleural space at the apex of the chest. It was considered that his condition would not permit of any further pre-operative investigation to make a diagnosis. Thoracotomy was accordingly undertaken on April 18, 1953, and the operation note was as follows:

"The eighth and subsequently the seventh right ribs resected. On opening the chest a very large quantity of dark red blood issued. An enormous tumour was found lying in the lower part of the

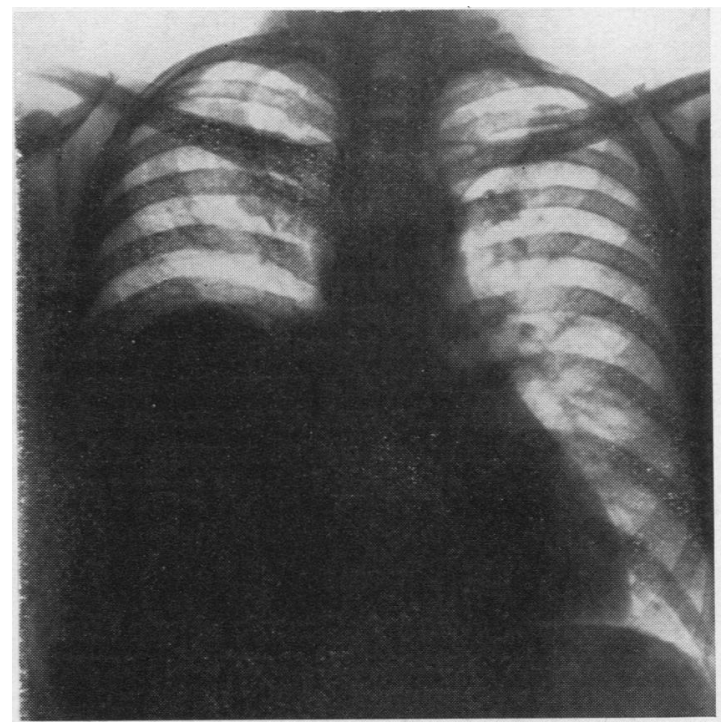

Fig. 2.-Pre-operative film showing large tumour in the right hemithorax. 
chest, very closely attached to the lung by numerous vascular adhesions. Vessels up to a centimetre in diameter coursed over the surface of the tumour. The tumour extended in front of the heart well beyond the midline and was attached to the pericardium and to the diaphragm. The adhesions to the lung were freed, and it was necessary to suture many of them on the lung side. One large vessel on the lung spurted freely, and obviously carried a direct supply from the pulmonary artery. The attachments to the diaphragm and lower part of the pericardium were broader, thicker, and less vascular. These were separated with some difficulty as the tumour was in the way and could not be retracted very well. After complete division it was possible to remove the tumour through the incision. All bleeding was then dealt with and two leaking areas of the lung were oversewn. The lung re-expanded readily and the chest was closed with drainage."

The patient made a straightforward recovery and is now back at full-time work. The cyanosis has disappeared. His exercise tolerance is good. Examination of the tumour showed that it weighed $2,400 \mathrm{~g}$. and was $20 \times 13 \mathrm{~cm}$. in size. It was encapsulated with a tough, fibrous structure composed of intersecting bundles with a few small cystic spaces (Fig. 3). Microscopically it was a simple fibroma.

\section{Discussion}

In the second case there was little doubt at operation that the tumour had arisen from the pleura overlying the diaphragm and the cardiophrenic angle, and in the first case an origin in the upper surface of the diaphragm seemed to be likely. At both operations the highly vascular adhesions to the lung suggested a secondary blood supply acquired as the growth extended. Possibly the enormous size reached by these and other tumours reported is due to the augmentation of their blood supply by pulmonary arterial blood. It would be of considerable interest to estimate the degree of shunt through these adhesions which act as a pulmonary arterio-venous fistula. In many of the reported cases there were clinical signs, such as finger clubbing, to suggest such a shunt. In our second patient before operation there was marked finger clubbing and dyspnoea out of proportion to the degree of pulmonary collapse. Unfortunately his condition did not permit of full investigation.

\section{SUMMARY}

Two cases of giant intrathoracic simple fibroma are reported, both successfully treated by operative removal. The literature is briefly reviewed. The necessity for further investigation of the physiological changes in these patients is noted and the
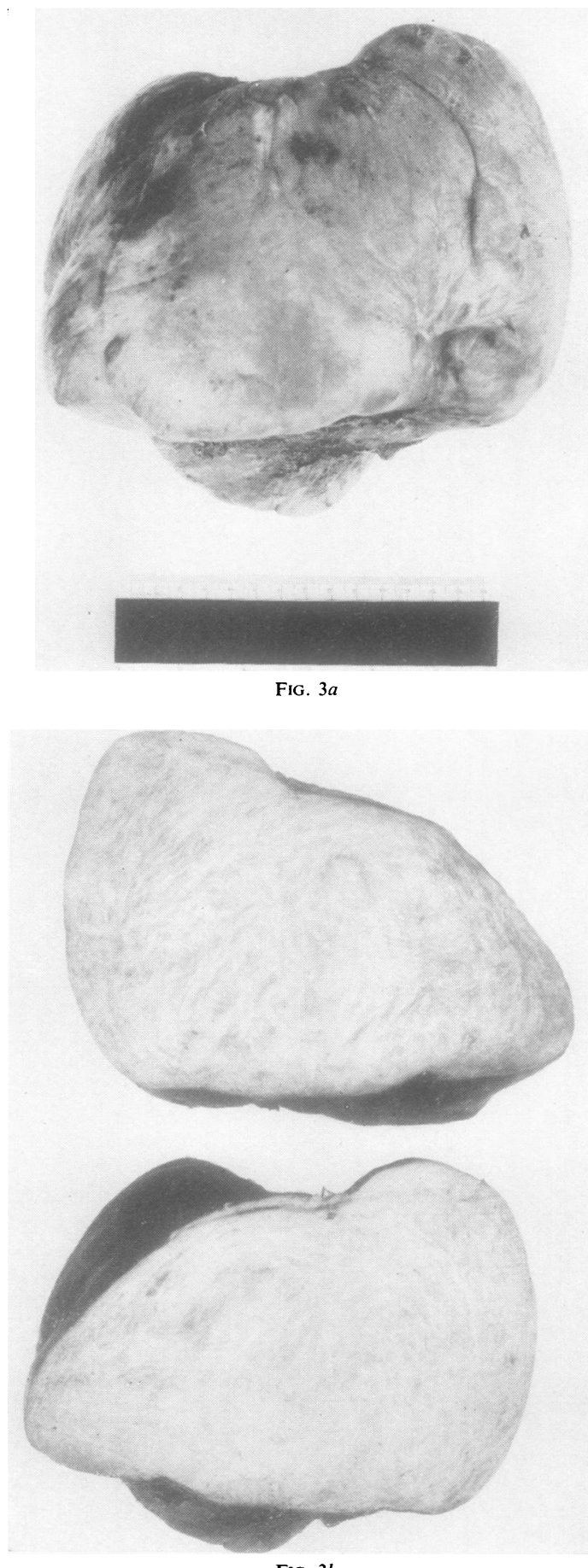

FIG. $3 b$

FIG. 3.-(a) Large solid encapsulated fibroma with surface haemorrhages; $(b)$ cut surface of tumour showing bundles of interlacing fibrous tissue. 
danger of diagnostic aspiration is underlined by our experience.

Our thanks are due to Mr. Ronald Edwards, whom one of us had the privilege of assisting with the first case, to Dr. Whitwell for the pathology reports, and to Dr. M. Davidson and Sir Clement Price Thomas for details of some previous cases.

\section{REFERENCES}

Alexander, B. (1896). Mag. orv. Arch., 5, 54.

Alexander, J. (1941). Ann. Surg., 114, 734

Baxter, S. G., and Munro, D. D. (1950). J. thorac. Surg., 19, 944. Blades, B. (1941). Amer. J. Surg., 54, 139.

- (1946). Ann. Surg., 123, 749 .

Bonamy, R. (1912). Paris chir., 4, 1051

Brewer, L. A., Jones, W. M. G., and Dolley, F. S. (1948). J. thorac Surg., 17, 439.

Burvill-Holmes, E., and Brody, W. (1932). Amer. J. med. Sci., 183, 679.
Clagett, O. T., and Hausmann, P. F. (1944). J. thorac. Surg.. 13, 6. Davidson, M. (1935). A Practical Manual of Diseases of the Chest p. 477. Oxford University Press, London.

Eskelund, V. (1951). Thorax, 6, 154.

Fawcett, A. W. (1945). Brit. med. J., 2, 425.

Gale, J. W., and Edwards, S. R. (1939). J. thorac. Surg., 9, 185.

Granché, M. (1868). Bull. Soc. anat. Paris, 43, 385.

Harper, F. R. (1939). J. thorac. Surg., 9, 132.

Horst, J. V., and Beatty, O. A. (1951)." Ohio St. med. J., 47, 138.

Hyman M. A., and Lederer, M. (1941). Arch. Path., Chicago, 31, 204.

Kinsella, T. J. (1939). In discussion on Gale, J. W., and Edwards, S. R. (1939), p. 193.

Nes, C. P. van (1921). Ned. T. Geneesk., 65, (2), 583.

Pollitzer, G., and Vaccarezza, O. A. (1946). An. Cáted. Patol. Tuberc. B. Aires, 8, 145.

Sante L R , (1931). Mentioned in A Text-Book of X-ray Diagnosis, (1st ed., 1938), ed. Shanks, S. C., Kerley, P., and Twining, E. W., vol. 1, p. 400. Lewis, London.

Susman, M. P. (1940). Aust. N.Z. J. Surg., 10, 194.

Thomas, C. Price (1953). Personal communication.

Tuohimaz, A. (1950). Ann. Chir. Gynaec. Fenn., 39, 206

Verna, J. F., Menso, M. V., Cueto Böttiger, A., and Luduena Funes, C. (1950). Bol. Soc. Cirug. Cordoba, 11, 311.

Weiss, A. G., and Delhaye, H. (1946). Mím. Acad. Chir. Paris, 72, 151 . 